\title{
A Simulation Model of the Automotive Power System Based on the Finite State Machine
}

\author{
Hongbin $\mathrm{Li}^{*}$ and Dong $\mathrm{Li}$
}

Transportation School of Ludong University, 186 Hongqizhong Road Yantai, 264025, China

\begin{abstract}
In order to validate the performance of the AMT (Automated Mechanical Transmission) control system by simulation experiment, a simulation model that can express the dynamic characteristic of the automotive power system during every phase of the vehicle driving process based on the finite state machine was proposed. Then a hard-in-loop half-real simulation system was established taking the simulation model as kernel. It was shown by the results of simulation experiments that the model could simulate the automotive power system effectively and could be used to evaluate the AMT control system.
\end{abstract}

Keywords: Automotive power system, finite state machine, simulation model.

\section{INTRODUCTION}

The requirements of comfort, safety and environmentalprotection for a heavy truck cannot be satisfied simultaneously adopting the classical automotive hand control transmission. So, the Automated Mechanical Transmission (AMT) by electrical control is an ideal solution for this issue $[1,2]$. During the developing process of AMT system, the simulation experiment is an important method. The kernel of the simulation experiment is the simulation model that expresses the dynamic characteristic of the vehicle's power system.

The whole power system model could be separated into three parts: the model which expresses the output torque of the engine, the model which expresses the resistance, the model which expresses the transmission system. There were a lot of researches on the engine output torque and resistance characteristic. The characteristic of the transmission system is researched in this paper. Now, the most common simulation model could only express the dynamic characteristic during one phase of the vehicle driving process [3-6].

To improve the simulation performance, a simulation model that can express the dynamic characteristic during every phase of the vehicle driving process is proposed based on the finite state machine.

\section{SIMULATION MODEL BASED ON FINITE STATE MACHINE}

During the normal driving process, the clutch is engaged, the gearbox is not shifted to neutral, the transmission system is combined as a whole. In this state, the driving torque on

*Address correspondence to this author at the Transportation School of Ludong University, 186 Hongqizhong Road Yantai, 264025, China;

Tel: 0086-535-6681847; Fax: 0086-535-6681847;

E-mail: hongbinlimv@163.com the transmission system is the output torque of the engine, the resistant torque is the overall resistance. But if the clutch is not engaged or the gearbox is shifted to neutral, the transmission system is separated to several parts, the driving torque and resistant torque on each part are different. So, the transmission system is not seemed as a whole in this paper. A finite state machine is established, and the characteristic of each part of the transmission system in different state is analysed when the simulation model is erected. The transmission system can be divided into three parts. The first part is the engine which includes the crank shaft of the engine and the input shaft of the clutch. The second part is the input shaft of the gearbox which includes the output shaft of the clutch and the input shaft of the gearbox. The third part is the output shaft of the gearbox which includes all of the components from the output shaft of the gearbox to the wheel. According the working estate of the clutch and gearbox, there are four states in the finite state machine of the transmission system. those are: the clutch is disengaged, the gearbox is not shifted to neutral; the clutch is engaged, the gearbox is not shifted to neutral; the clutch is disengaged, the gearbox is shifted to neutral; the clutch is engaged, the gearbox is shifted to neutral.

2.1. The State that the Clutch was Disengaged, the Gearbox was not Shifted to Neutral

During the startup process, the vehicle is in this state. In the transmission system, the dynamic characteristic of the clutch is complex. The torque generated by the engine is transferred to the gearbox depending on the friction between the active tray and the driven tray. The torque transferring ability of the clutch is lie on the pressure of the friction surface, the action radius of the friction force, the material of the frictional fit and the number of the working surface. The maximal frictional torque is [7]:

$T_{c l \text { max }}=F_{c l} * \mu * R_{c l} * Z$ 
$F_{c l}$-the pressure on the frictional surface.

$\mu$-the frictional coefficient.

$R_{c l^{-}}$the action radius of clutch.

$Z_{c l^{-}}$the number of the working surface.

When the clutch is disengaged, the resistant torque on the engine part is the frictional torque of the clutch, the driving torque on the gearbox input part is the frictional torque of the clutch too.

So, in this state, the model of the engine part is:

$T_{e}-T_{c l}-\mu_{e} \omega_{e}=I_{e} \dot{\omega}_{e}$

$T_{e}$-the torque generated by the engine.

$T_{c l}$-the frictional torque that was transferred by the clutch.

$\mu_{e}$ - the frictional coefficient of the engine part.

$\omega_{e}$-the rotational speed of the engine.

$I_{e}$-the rotational inertia of the engine part.

The model of the gearbox input part is:

$T_{c l}-T_{\text {loadeqgin }}-\left(\mu_{\text {gin }}+\mu_{\text {gouteggin }}\right) \omega_{\text {gin }}$

$=\left(I_{\text {gin }}+I_{\text {gouteggin }}\right) \dot{\omega}_{\text {gin }}$

$T_{\text {loadeqgin }}$-the equivalent resistant torque on the input shaft of the gearbox which lie on the shift.

$\mu_{\text {gin }}$-the frictional coefficient of the gearbox input part.

$\mu_{\text {gouteqgin }}$-the equivalent frictional coefficient of the gearbox output part which lie on the shift.

$I_{\text {gin }}$ - the rotational inertia of the gearbox input part.

$I_{\text {gouteqgin }}$ - the equivalent rotational inertia of the gearbox output part which lie on the shift.

$\omega_{\text {gin }}$ - the rotational inertia of input shaft of the gearbox.

The model of the gearbox output part is:

$T_{\text {cleqgout }}-T_{\text {load }}-\left(\mu_{\text {gineqgout }}+\mu_{\text {gout }}\right) \omega_{\text {gout }}$

$=\left(I_{\text {gingout }}+I_{\text {gout }}\right) \dot{\omega}_{\text {gout }}$

$T_{\text {cleqgout }}$ the equivalent torque transferred by the clutch which lie on the shift.

$T_{\text {load }}$ the resistant torque.

$\mu_{\text {gineqgout }}{ }^{-}$the equivalent frictional coefficient of the gearbox input part which lie on the shift.

$\mu_{\text {gout }^{-}}$the frictional coefficient of the gearbox output part.

$I_{\text {gineqgout }}$ the equivalent rotational inertia of the gearbox input part which lie on the shift.

$I_{\text {gout }}{ }^{-}$the rotational inertia of gearbox output part.

$\omega_{\text {gout }}{ }^{-}$the rotational inertia of output shaft of the gearbox.

\subsection{The State that the Clutch was Engaged, the Gearbox was not Shifted to Neutral}

During the normal driving process, the vehicle is in this state. While the torque that the clutch can transfer is larger than the resistant torque and the engine speed equal the rotational speed of the input shaft of the gearbox, the clutch depart from the disengaged state and enter into the engaged state.

In this state, the model of the engine part is:

$$
\begin{aligned}
& T_{e}-T_{\text {loadeqe }}-\left(\mu_{e}+\mu_{\text {gineqe }}+\mu_{\text {gouteqe }}\right) \omega_{e} \\
& =\left(I_{e}+I_{\text {gineqe }}+I_{\text {gouteqe }}\right) \dot{\omega}_{e}
\end{aligned}
$$

$T_{\text {loadeqe }}$ the equivalent resistant torque on the crank shaft of the engine which lie on the shift.

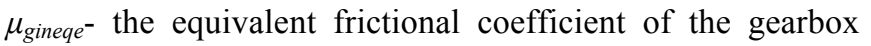
input part which lie on the shift.

$\mu_{\text {gouteqe }}$ the equivalent frictional coefficient of the gearbox output part which lie on the shift.

$I_{\text {gineqe }}$ - the equivalent rotational inertia of the gearbox input part which lie on the shift.

$I_{\text {gouteqe }}$ - the equivalent rotational inertia of the gearbox output part which lie on the shift.

The model of the gearbox input part is:

$$
\begin{aligned}
& T_{\text {eeqgin }}-T_{\text {loadeggin }}-\left(\mu_{\text {eeqgin }}+\mu_{\text {gin }}+\mu_{\text {gouteqgin }}\right) \omega_{\text {gin }} \\
& =\left(I_{\text {eeqgin }}+I_{\text {gin }}+I_{\text {gouteqgin }}\right) \dot{\omega}_{\text {gin }}
\end{aligned}
$$

$T_{\text {eeqgin }}$ - the equivalent torque generated by the engine which lie on the shift.

$\mu_{\text {eeqgin }}$ the equivalent frictional coefficient of the engine part which lie on the shift.

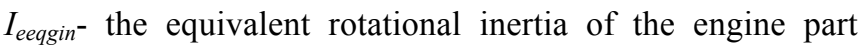
which lie on the shift.

The model of the gearbox output part is:

$$
\begin{aligned}
& T_{\text {eeqgout }}-T_{\text {load }}-\left(\mu_{\text {eeqgout }}+\mu_{\text {gineqgout }}+\mu_{\text {gout }}\right) \omega_{\text {gout }} \\
& =\left(I_{\text {eeqgout }}+I_{\text {gineqgout }}+I_{\text {gout }}\right) \dot{\omega}_{\text {gout }}
\end{aligned}
$$

$T_{\text {eeqgout }}$ the equivalent torque generated by the engine which lie on the shift.

$\mu_{\text {eeqgout }}$ the equivalent frictional coefficient of the engine part which lie on the shift.

$I_{\text {eeqgout }}$ the equivalent rotational inertia of the engine part which lie on the shift.

\subsection{The State that the Clutch was Disengaged, the Gearbox was Shifted to Neutral}

During the shifting process, the vehicle is in this state.

In this state, the model of the engine part is: 
$T_{e}-T_{c l}-\mu_{e} \omega_{e}=I_{e} \dot{\omega}_{e}$

The model of the gearbox input part is:

$T_{c l}-\mu_{g i n} \omega_{g i n}=I_{g i n} \dot{\omega}_{g i n}$

The model of the gearbox output part is:

$-T_{\text {load }}-\mu_{\text {gout }} \omega_{\text {gout }}=I_{\text {gout }} \dot{\omega}_{\text {gout }}$

\subsection{The State that the Clutch was Engaged, the Gearbox was Shifted to Neutral}

While the rotational speed of the gearbox input shaft is regulated by the engine during the shifting process, the vehicle is in this state.

In this state, the model of the engine part is:

$T_{e}-\left(\mu_{e}+\mu_{\text {gineqe }}\right) \omega_{e}=\left(I_{e}+I_{\text {gineqe }}\right) \dot{\omega}_{e}$

The model of the gearbox input part is:

$T_{\text {eeqgin }}-\left(\mu_{\text {eeqgin }}+\mu_{\text {gin }}\right) \omega_{\text {gin }}=\left(I_{\text {eeqgin }}+I_{\text {gin }}\right) \dot{\omega}_{\text {gine }}$

The model of the gearbox output part is:

$-T_{\text {load }}-\mu_{\text {gout }} \omega_{\text {gout }}=I_{\text {gout }} \dot{\omega}_{\text {gout }}$

It is shown from (2)-(13) that the model form of each part in different state is same and the value of the output torque, resistant torque, frictional coefficient, rotational inertia are different.

\section{SIMULATION SYSTEM}

In order to validate the performance of the AMT controlling system, a hard-in-loop half-real simulation system is established based on the simulation model proposed above. The structure of the system is shown in Fig. (1).

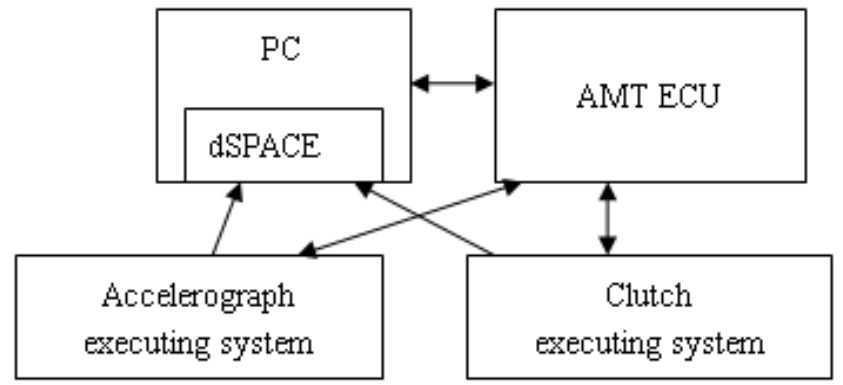

Fig. (1). Structure of the simulation system.

In this system, the dSPACE is used to simulate the dynamic characteristic according to some real information. These informations include the accelerograph position from the accelerograph executing system, the clutch position from the clutch execution system and the shifting signal from the AMT ECU. The dSPACE also transfer information to AMT ECU such as engine speed, vehicle speed etc. The accelerograph Clutchexecuting system and the clutch executing system are controlled by AMT ECU.

The dynamic model based on finite state machine used in dSPACE is programmed in MATLAB Simulink. The dynamic model of the engine part is shown in Fig. (2). In which, the Chart is the finite state machine.

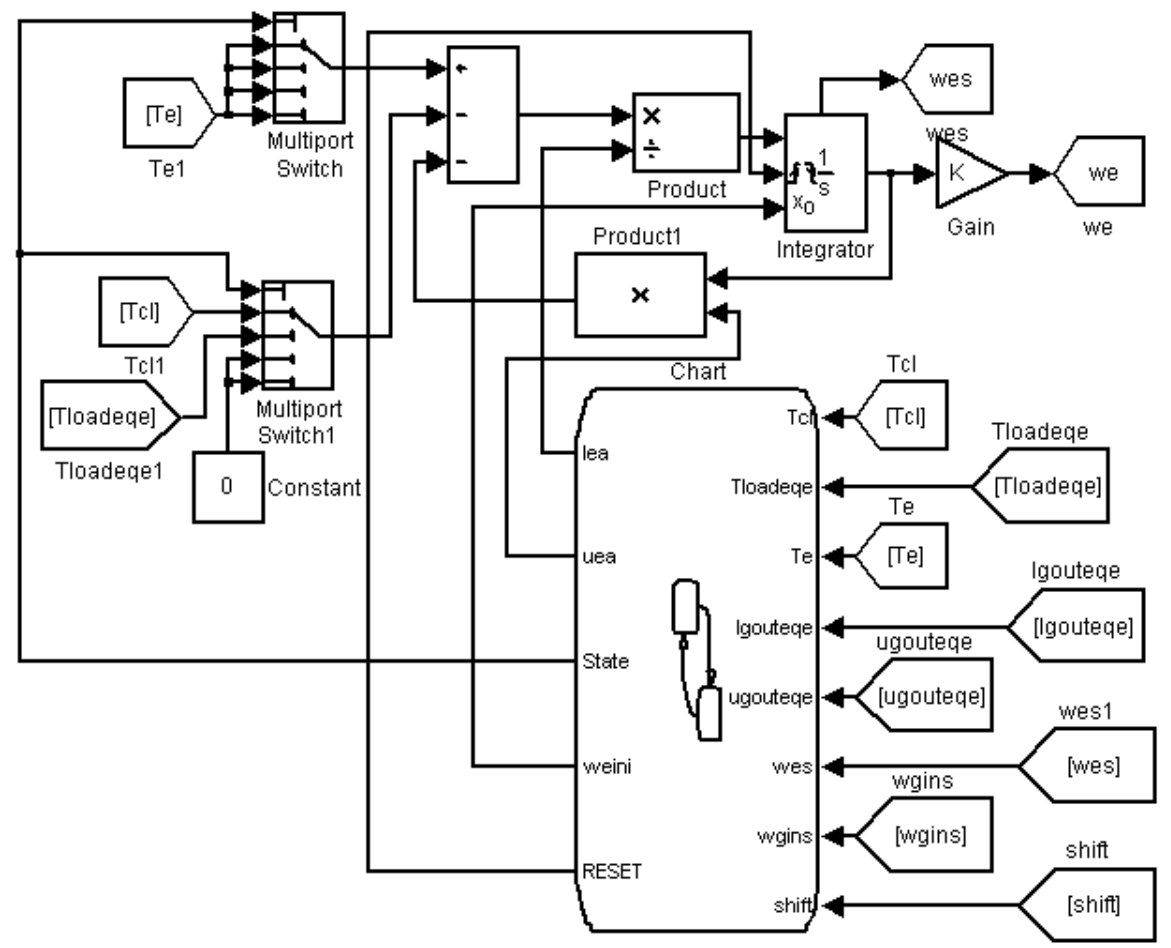

Fig. (2). The simulation dynamic model of the engine part. 
The input variable of the Chart are Tcl, Tloadeqe, Te, Igouteqe, $\mu$ gouteqe generated by corresponding sub-system, whose meanings are the same as them in the equations above. The $\omega$ ges, $\omega$ ginsshift are also the input variable of the Chart. The $\omega$ ges exported from the state port of the integrator expresses the estate of the integrator. The wgins exported from the state port of the integrator in the gearbox input part sub-system expresses the estate of the integrator. The shift is imported from the AMT ECU, it expresses the current shift.

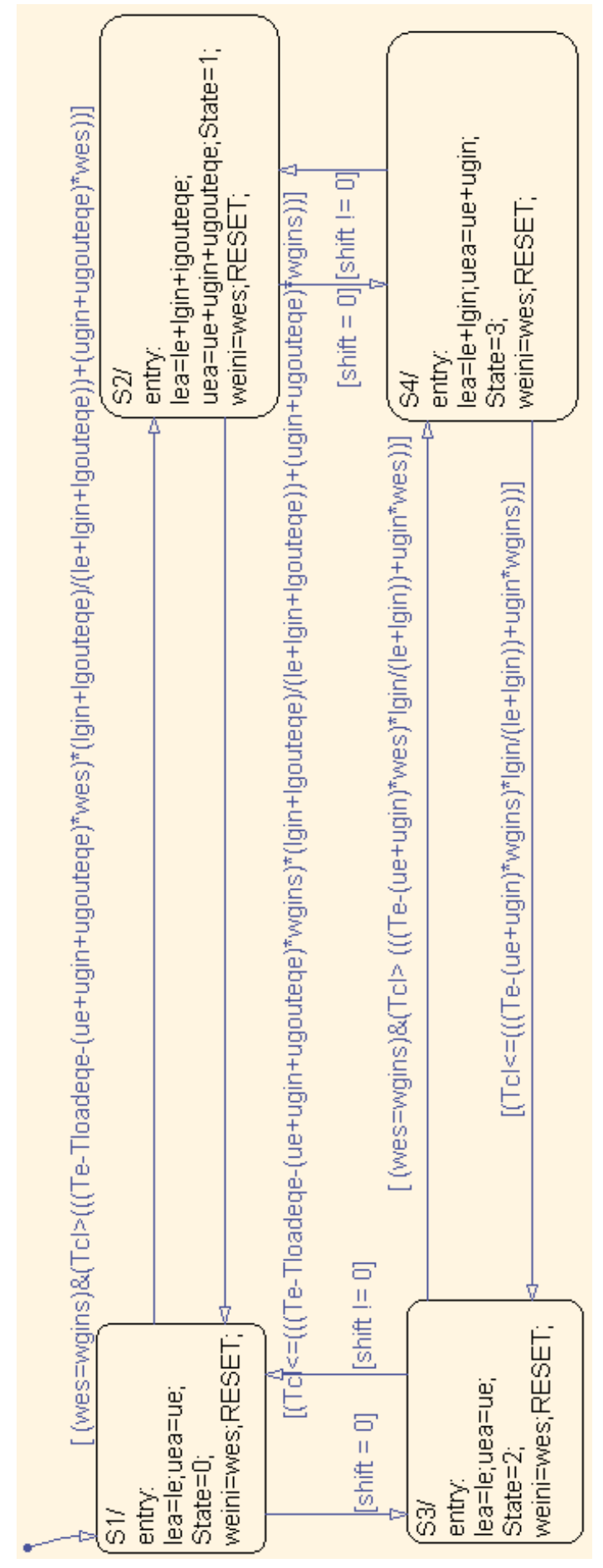

Fig. (3). The state chart of the engine part.
Except these input variables, the chart also has several output variable. The Iea expresses the equivalent rotational inertia of the engine part sub-system in each state, the $\mu$ ea expresses the equivalent frictional coefficient of the engine part sub-system in each state, the weini expresses the integral initial value while the state changes.

When the state of the system changes, the chart exports the Iea, $\mu$ ea, weini, State according the new state. The equivalent engine torque and the resistant torque in each state is controlled based on the State. Besides, the Chart generates RESET signal to reset the integrator while the state changes.

The chart is shown in Fig. (3).

The S1 expresses the state in which the clutch is disengaged, the gearbox is not shifted to neutral, the S2 expresses the state that the clutch is engaged, the gearbox is not shifted to neutral, the S3 expresses the state that the clutch is disengaged, the gearbox is shifted to neutral, the S4 expresses the state that the clutch is engaged, the gearbox is shifted to neutral. The initial state of the system is S1. The entry of each state express the actions that should be done while entering the state. These actions include calculating the input torque, resistant torque, frictional coefficient, rotational inertia of the engine part in this state and resetting the initial value of the integrator.

In the $\mathrm{S} 1$ state, if

$\omega_{e s}=\omega_{\text {gins }}$

and,

$$
\begin{aligned}
& T_{c l}>\left(\left(\left(T_{e}-T_{\text {loadeqe }}-\left(\mu_{e}+\mu_{\text {gin }}+\mu_{\text {gout }}\right) * \omega_{\text {es }}\right)\right.\right. \\
& \left.*\left(I_{\text {gin }}+I_{\text {gouteqe }}\right) /\left(I_{e}+I_{\text {gin }}+I_{\text {gouteqe }}\right)\right) \\
& \left.+\left(\mu_{\text {gin }}+\mu_{\text {gouteqe }}\right) * \omega_{e s}\right)
\end{aligned}
$$

The system enter into the $\mathrm{S} 2$ state.

In the equation (15), the acceleration of the vehicle system is calculated firstly using the effect of the difference of torque between the engine torque and the total torque of the friction and resistance. Then the torque can arise the state conversion which is calculated according the acceleration.

Similarly, in the S1 state, if

$T_{c l} \leq\left(\left(\left(T_{e}-T_{\text {loadeqe }}-\left(\mu_{e}+\mu_{\text {gin }}+\mu_{\text {gout }}\right) * \omega_{\text {gins }}\right)\right.\right.$
$\left.*\left(I_{\text {gin }}+I_{\text {gouteqe }}\right) /\left(I_{e}+I_{\text {gin }}+I_{\text {gouteqe }}\right)\right)$
$\left.+\left(\mu_{\text {gin }}+\mu_{\text {gouteqe }}\right) * \omega_{\text {gins }}\right)$

The system enter into the $\mathrm{S} 2$ state.

In the S1 State, if the shift is equal to 0 , the system enter into the S3 state. In the S3 State, if the shift does not equal to 0 , The system enter into the $\mathrm{S} 31$ state.

The Simulink model can run in dSPACE after being compiled. Fig. (4) shows the interface of ControlDesk, which can show the parameter during the simulation process.

\section{SIMULATION EXAMPLE}




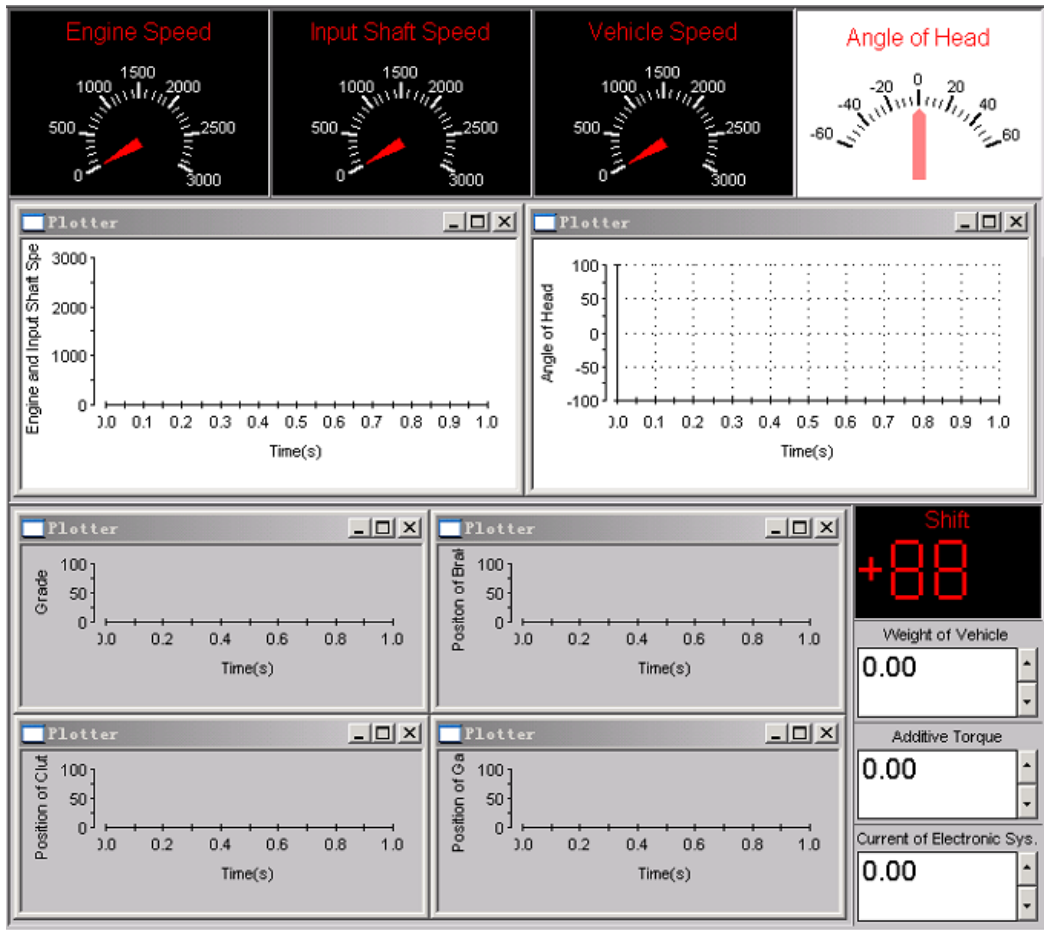

Fig. (4). Interface of the experiment system.

Fig. (5) shows the startup process of the vehicle control by the AMT ECU. Fig. (6) shows one down-shift process of the vehicle control by the AMT ECU. These results are close to the results of the actual experiment.

\section{CONCLUSION}
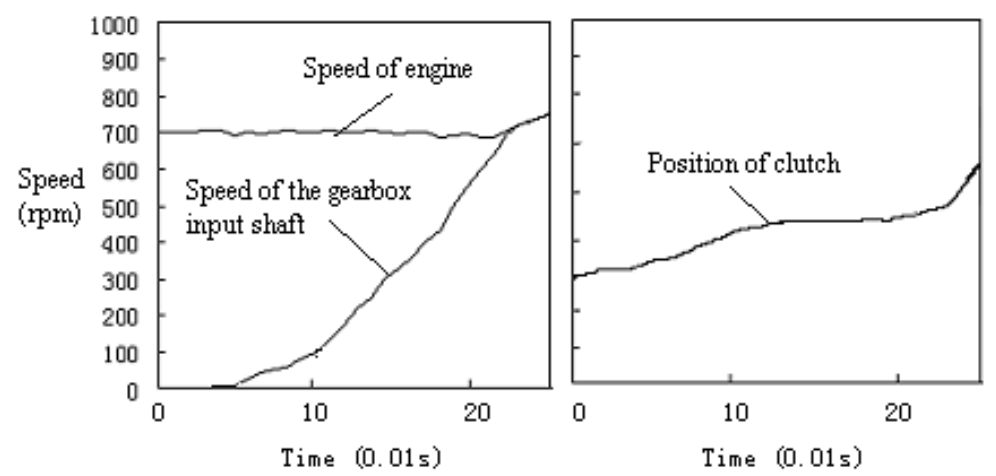

Fig. (5). Simulation curve of the startup process.
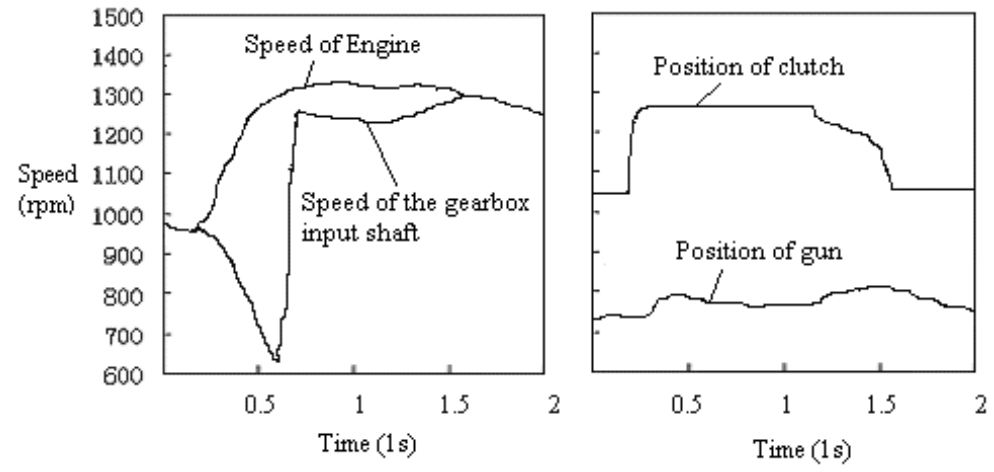

Fig. (6). Simulation curve of the down-shift process.
From the result of the simulation experiment, it is shown that the dynamic characteristic during every phase of the vehicle driving process can be simulated using the simulation model based on finite state machine. So the model is adapted to validate the performance of the AMT 
control system.

\section{CONFLICT OF INTEREST}

The authors confirm that this article content has no conflict of interest.

\section{ACKNOWLEDGEMENTS}

The project was supported by the Research Award Fund for Outstanding Young Scientists of Shandong Province in China (Grant No. 2011BSB01183).

\section{REFERENCES}

[1] Q. Guihe, F. Juxin, Z. Hongkun, and Ge Anlin, "Microcomputer control system of automated mechanical transmission", Automotive Engineering, vol. 21, pp. 21-25, 1999.

[2] G. Liqiang, L. Enmao, and Z. Jianwu, "Automated mechanical transmission with 87C196CB Microcontroller", Machine Tool and Hydraulics, vol. 5, pp. 123-124, 2002.

[3] G. Anlin, J. Jiaji, and W. Wenzhi, "Research on automatic mechanical transmission and its dynamic simulation test stand", Chinese Automotive Engineering, vol. 3, pp. 35-43, 1990.

[4] L. Mianzo, "A transmission model for hard-ware-in-loop powertrain control system software development", In: Proceedings of the 2000 IEEE International Conference of the Control Applications, Alaska, USA. September, pp. 1-8. 2000

[5] L. Gliemlo and F. Vasca, "Engagement Control for Automotive Dry Clutch", In: Proceedings of the American Control Conference, Chicago, USA. June, 2000, pp. 1016-1017.

[6] F. Garofalo, L. Glielmo, and F. Vasca, "Smooth Engagement for Automotive Dry Clutch", In: Proceedings of the 40th IEEE Conference on Decision and Control, Orlando, USA. December, 2001, pp. 529-534.

[7] X. Shian, X. Debing, and L. Weixin, "The clutch," Peoples Communication Press, Beijing, 1981.

(C) Li and Li; Licensee Bentham Open.

This is an open access article licensed under the terms of the Creative Commons Attribution Non-Commercial License (http://creativecommons.org/licenses/ by-nc/3.0/) which permits unrestricted, non-commercial use, distribution and reproduction in any medium, provided the work is properly cited. 